\title{
The Inapplicability of Huebner's Semantic Wheel to Some English Nps: A Debatable Viewpoint at the Deeper Level
}

\author{
Thekra Mohammed Abdullah Yehia
}

Department of Linguistics, University of Mysore, City of Mysore, India

\section{Email address:}

thekrayehia@gmail.com

\section{To cite this article:}

Thekra Mohammed Abdullah Yehia. The Inapplicability of Huebner's Semantic Wheel to Some English Nps: A Debatable Viewpoint at the Deeper Level. International Journal of Language and Linguistics. Vol. 4, No. 3, 2016, pp. 96-102. doi: 10.11648/j.ij11.20160403.12

Received: April 4, 2016; Accepted: April 15,2016; Published: April 27, 2016

\begin{abstract}
The current paper is an argumentative outlook of Huebner's Semantic Wheel. The researcher wanted to investigate the difficulties in the use of English articles by the Yemeni EFL learners. Huebner's Semantic Wheel was used to identify the most frequently substituted NPs. However, some shortcomings in the applicability of such model in some cases were found. The curiosity of discovering the reasons behind the inapplicability of Huebner's model to some noun phrases led to some notable conclusions; which are put, here, for discussion.
\end{abstract}

Keywords: Huebner's Semantic Wheel, Definiteness, Specificity, Transfer, Article System

\section{Introduction}

Articles are function words that carry many indications about the identity of the NPs they modify (i.e. specificity, definitiveness and the count status and number). The identifications between definiteness and specificity are based mainly on discourse analysis or upon the speaker/writer's intention. Ionin, Ko and Wexler (2004) suggest that the features of definiteness/indefiniteness $[ \pm$ definite] are built upon both the speaker/writer and the hearer/reader's knowledge, whereas the features of specificity/nonspecificity $[ \pm$ specific] are built upon the speaker/writer's knowledge only. Specificity means that if the speaker is referring to a noun that both speaker and hearer know, the noun is modified by the definite article (the), e.g. Everybody admired the watch you gifted me. And when the speaker is referring to a noun that is only known to the speaker; but not the hearer; here, the noun is modified by either the indefinite article (a/an), depending on the phonetic realization of the initial grapheme of the noun to be modified, e.g. Yesterday, $I$ got a good-looking watch. Likewise, L1 article users have various ways of encoding specificity, noun countability and presumed hearer's knowledge within their L1 article system.

\subsection{Huebner's Semantic Wheel}

Huebner (1983) combined the features of specific reference $([ \pm \mathrm{SR}])$ and presumed hearer's knowledge $([ \pm \mathrm{HK}])$ to form four distinct quadrants.
Non-generic definites

Referential indefinites

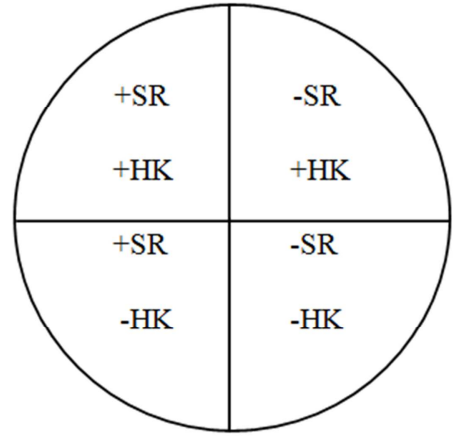

Non-referential indefinites
Generic nouns

Figure 1. Huebner's Semantic Wheel. 
As figure (1) shows within Huebner's system there are four types of NPs. Figure (2) gives more declarative description of Huebner's Semantic Wheel in terms of the features of specificity and definitiveness.

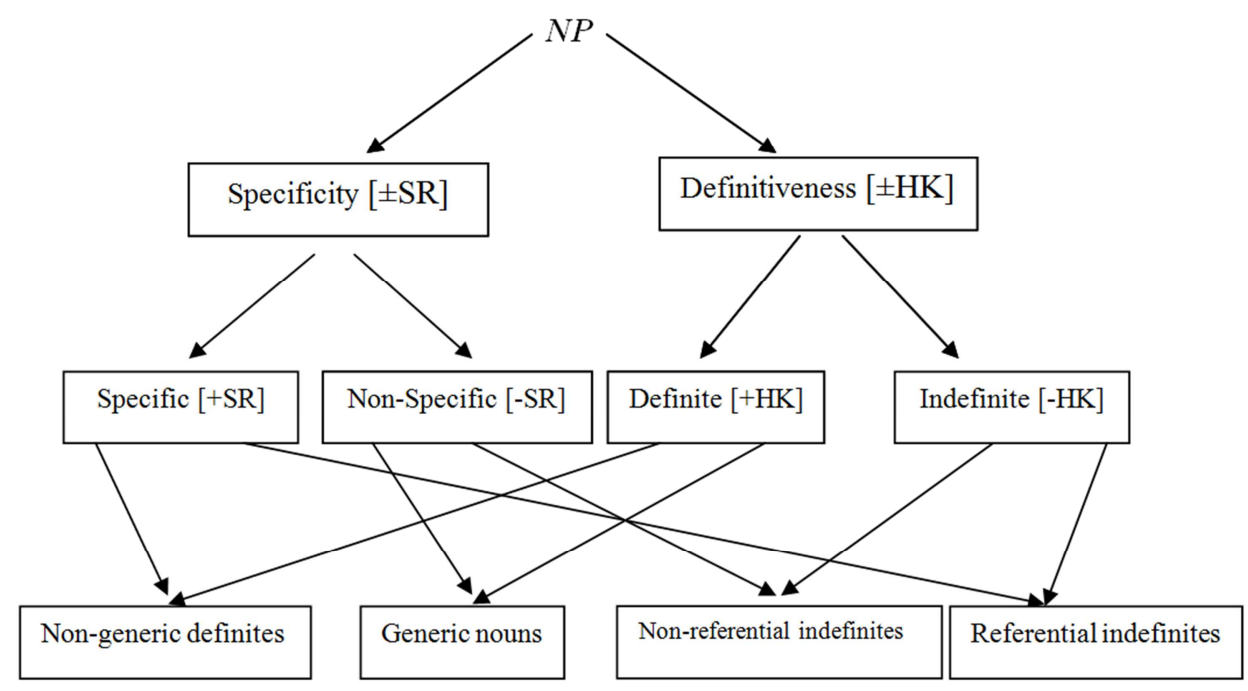

Figure 2. The Semantic Features of Huebner's NPs System in Terms of Specificity and Definitiveness.

According to figures (1) and (2) there are four types of English noun phrases.

\subsection{The Quatrain NPs of Huebner's Semantic Wheel}

A generic noun phrase is a noun phrase that does not refer to a specific (set of) individual(s), but rather to a kind or class of individuals. The noun phrases $([-\mathrm{SR},+\mathrm{HK}])$ are used to introduce generic nouns; with which all three articles can be used. In terms of countability, as figure (3) shows, these noun phrases take (a / an) for generic singular countable nouns (e.g., Sue held a dog) and (Ø) or (the) for generic plural count nouns as:

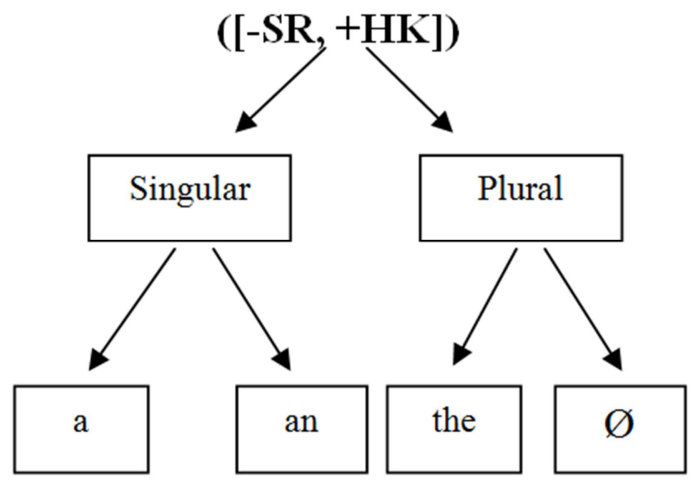

Figure 3. Generic Noun Phrase \& Countability.

Generic nouns can be singular indefinite as in the statement "A friend in need is a friend indeed".

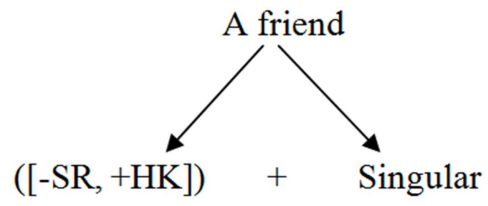

(Generic noun)
Despite the indefinite article, the noun 'friend' is generic because the speaker is not talking about a specific friend.

Generic nouns can also be plural definite as in "The friends help in need are the friends indeed".

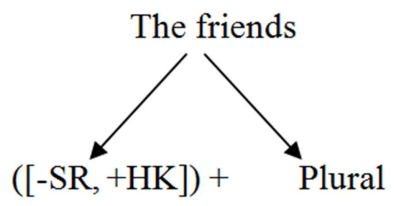

(Generic noun)

However, definite generic Nps are syntactically singular as in the statement 'The gang kidnapped the trader'.

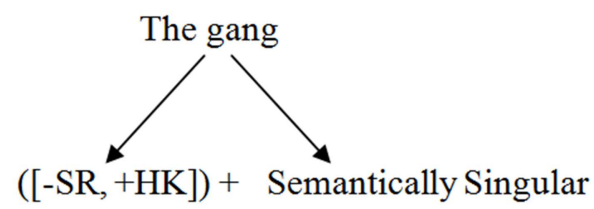

(Generic noun)

Generic nouns can also be plural zero-articled when as in " $\varnothing$ friends in need are $\varnothing$ friends indeed".

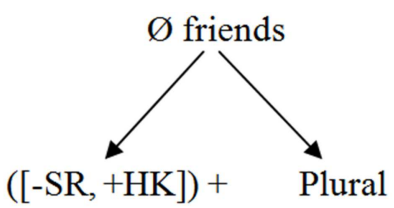

\section{(Generic noun)}

The noun phrases $([+\mathrm{SR},-\mathrm{HK}])$, referential indefinites, are used to introduce nouns that the speakers have in mind while the hearer have no knowledge of. The noun phrases of this type take (a/an) for singular count nouns and (Ø) for non- 
count and plural count nouns. Figure 4. below demonstrates the the use of articles in the referential indefinite noun phrases in terms of countability.

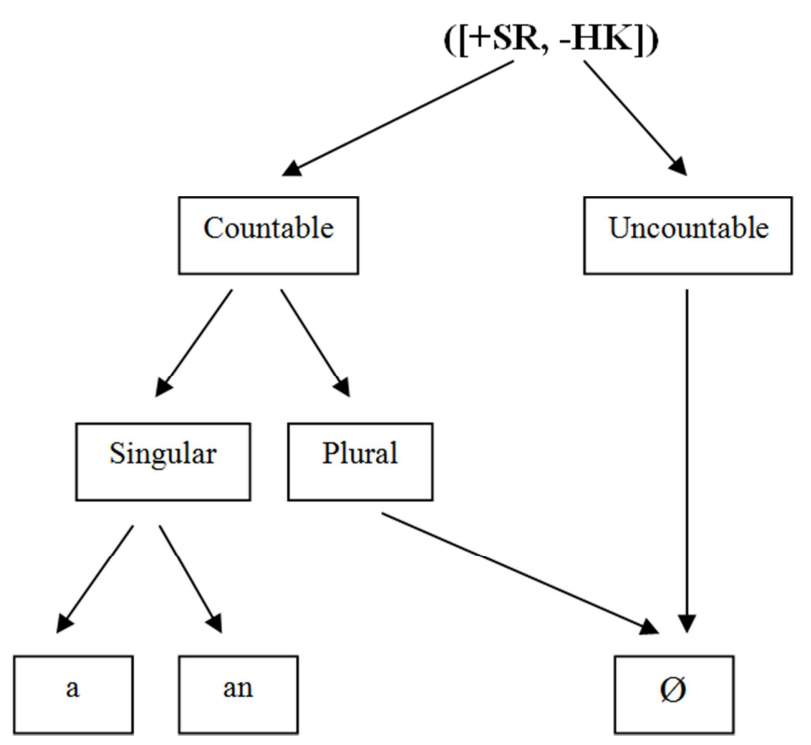

Figure 4. Referential Indefinite Noun Phrase \& Countability.

e.g.

- Yemeni men like to put a jampya (a dagger-like with curved edge and sharp blade).

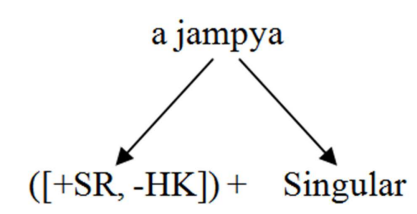

(Referential noun)

- Putting jampyas is a cultural sign of Yemeni men.

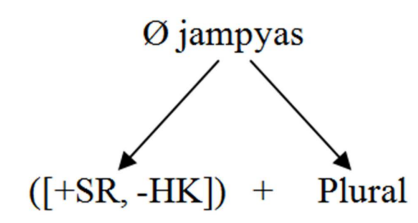

\section{(Referential noun)}

- Kabsa tastes very delicious.

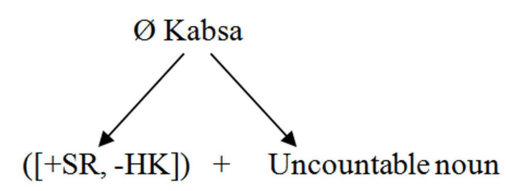

(Referential noun)

The noun phrases ([-SR, -HK]), non-referential indefinites, are used to introduce nouns that neither speakers have in mind; nor the hearer have knowledge of. Just as figure (5) below shows, the noun phrases of this type take (a/an) for singular count nouns and $(\varnothing)$ for non-count and plural count nouns:

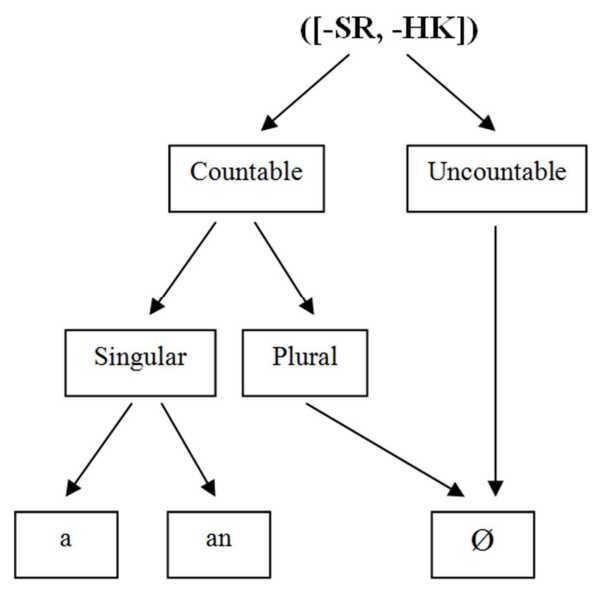

Figure 5. Non-referential Indefinites Noun Phrase \& Countability.

e.g.

- I heard that a bank got robbed yesterday. $=[a / a n$ + singular non-referential noun]

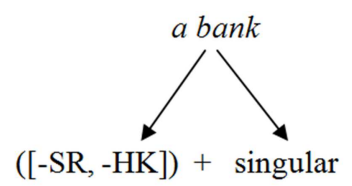

(Non-referential noun)

- Kindness is a sign of real humanity.

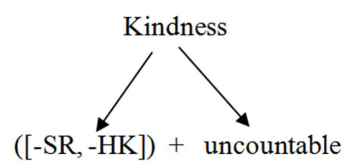

(Non-referential noun)

- I heard that new animals have been brought to the zoo.

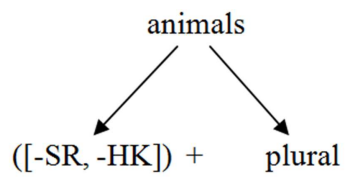

(Non-referential noun)

The noun phrases $([+\mathrm{SR},+\mathrm{HK}])$, non-generic definite, are used to introduce non-generic nouns. The article (the) is used to indicate a specific noun known to both the speaker and hearer:

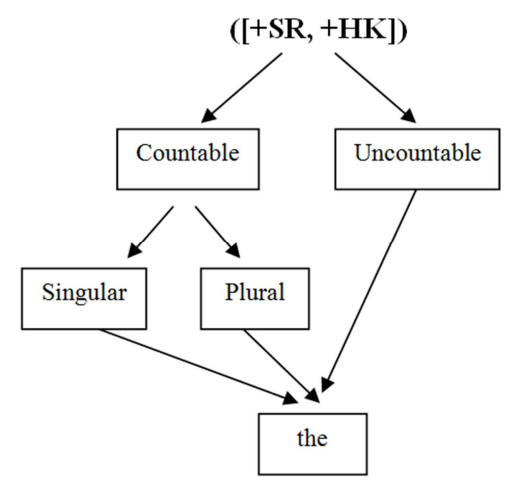

Figure 6. Non-generic Definite Noun Phrase \& Countability. 
e.g.

1. The president was on a diplomatic tour for the past three days. $([+\mathrm{SR},+\mathrm{HK}])=[$ non-generic noun $]$

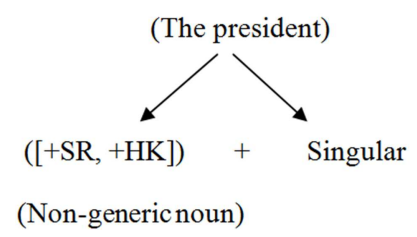

2. The stars look very beautiful at night. ([+SR, $+\mathrm{HK}])=[$ non-generic noun $]$

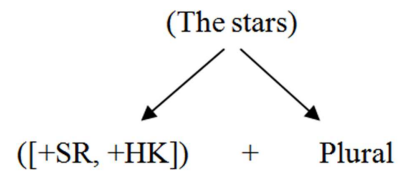

(Non-generic noun)

3. Then, we add the syrup that we have already prepared.

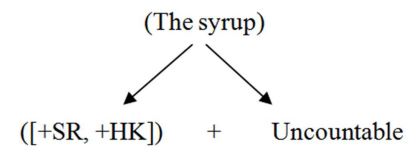

(Non-generic noun)

\section{Discussion}

Though English articles (the, a/an, and Ø) are pedagogically introduced at early stages of English language courses, it has been noticed that EFL learners still find it difficult to accurately master their uses at late stages. Some linguists, like Huebner, tried to ease the task by introducing a model of four English Nps; which, according to his claim, is applicable to all English Nps. The discussion of the fulfillment of this claim will be handled from three different perspectives: grammaticality, discourse, and the consideration of the learner's first language article system.

\subsection{Grammaticality}

\subsubsection{The Inapplicability of Huebner's Semantic Wheel to} Some NPs

There are some English NPs that do not belong to any of Huebner's types; for example, the $\mathrm{Np}$ (Ø school) in the sentence (we study English at school).

In the current statement, and according to Huebner's semantic wheel, 'school' can be considered a generic noun as the speaker is not talking about a specific school. Such generic Nps take indefinite articles when they are singular count nouns. So the noun phrase will be 'a school'.

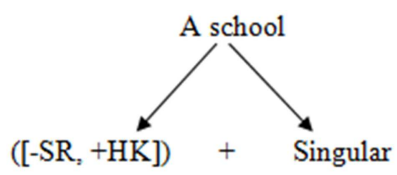

(Generic noun)
If we consider definiteness/indefiniteness [ \pm definite], both the speaker's and the hearer's knowledge of the school, then the Np has either possibilities:

1. It can be a referential indefinite noun phrase ([+SR, $\mathrm{HK}]$ ) if the hearer has no knowledge of the school the speaker talks about and it will be 'a school'.

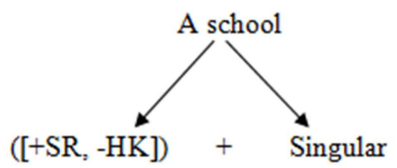

(Referential noun)

2. It can be a non-generic definite noun phrase ([+SR, $+\mathrm{HK}])$ if the hearer has knowledge of the school the speaker talks about and it will be 'the school'.

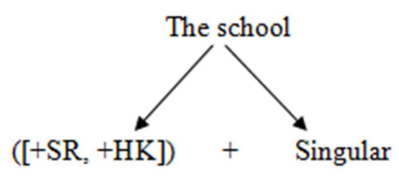

(Non-generic noun)

However, none of the possibilities mentioned above is grammatically correct as the noun 'school' is zero-articled in this context.

\subsubsection{The Confusion Arose from the Multiplicity of Possible NP Realizations}

Besides, in prepositional phrases like 'at the park', 'at the bank', and 'in the hospital',...etc the singular nouns 'park', 'bank', and 'hospital' can be, according to Huebner's Semantic Wheel, generic noun $([+\mathrm{SR},-\mathrm{HK}])$ in case the speaker is not talking about a specific bank, for example. In such semantic condition, the indefinite articles (a/an) are the only possible choices.

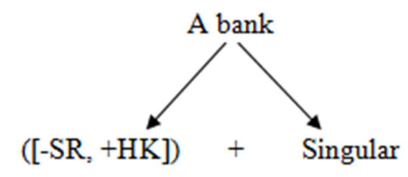

(Generic noun)

In terms of definiteness/indefiniteness [ \pm definite], the consideration of both the speaker's and the hearer's knowledge of the thing being talked about, the $\mathrm{Np}$ can be :

1. a referential indefinite $([+\mathrm{SR},-\mathrm{HK}])$ if the hearer has no knowledge of the bank the speaker talks about and the NP will be realized as 'a bank'.

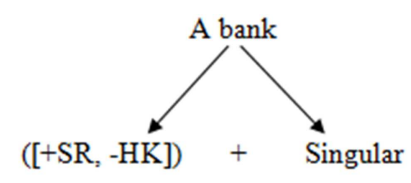

(Referential noun)

2. a non-generic definite $([+\mathrm{SR},+\mathrm{HK}])$ if the hearer has knowledge of the school the speaker talks about and it will be 'the bank'. 


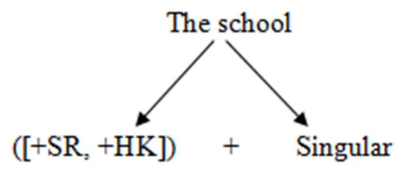

(Non-generic noun)

Though there are many NP possibilities according to Huebner's semantic wheel, the last possibility, (Non-generic noun) $([+\mathrm{SR},+\mathrm{HK}])$, is the only grammatically correct NP in this context.

Likewise, in a statement like "I am in the hospital", in terms of specificity speaker know the meaning of hospital; but in terms of definiteness, the hearer have no idea which hospital the speaker exactly is talking about. Thus, the use of the indefinite articles (a/an) is grammatically incorrect though (the) is holding the meaning and function of indefinite article in this context.

\subsubsection{The Partial Applicability of Huebner's Semantic Wheel to Some NPs}

The disease name 'Malaria' is always zero-articled, referential $\mathrm{Np}$. For example, 'Every year, thousands of Africans die because of Malaria'.

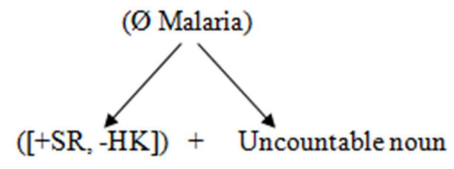

(Referential noun)

Though regarding definiteness, the use of 'the' before the noun is more probable as 'Malaria' is widely famous disease; yet it is not correct.

\subsection{Discourse}

\subsubsection{The Mismatch Between the Surface Structure and the Underlying Functioning of Articles in Some Contexts}

Sometimes, some articles function as another word class at the semantic level in some contexts; which results in mismatch between the surface structure and the underlying functioning. e.g He makes ten thousand dollars a year.

The noun phrase (a year), separately, is a $([-\mathrm{SR},+\mathrm{HK}])$ noun phrase used to introduce the generic indefinite singular noun 'year' in the singular case. However, the function and meaning of the noun phrase 'a year' completely changed when we consider the sentence as a whole entity, context. ' $a$ ' is functioning as a preposition with the meaning of 'per'.

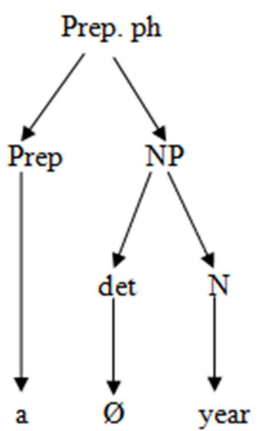

Accordingly, 'a year' is a prepositional phrase. Huebner's Semantic Wheel dealt with noun phrases concretely as an article-noun compilation depending on specificity, noun countability and presumed hearer's knowledge. He ignored the context in which the identity of the phrase is clearly visualized as it is a part of the whole.

\subsubsection{The Effect of the Noun Count Realization at the Semantic Level}

In the sentence "The tiger is in danger of becoming extinct." the noun phrase 'the tiger' is definite generic singular:

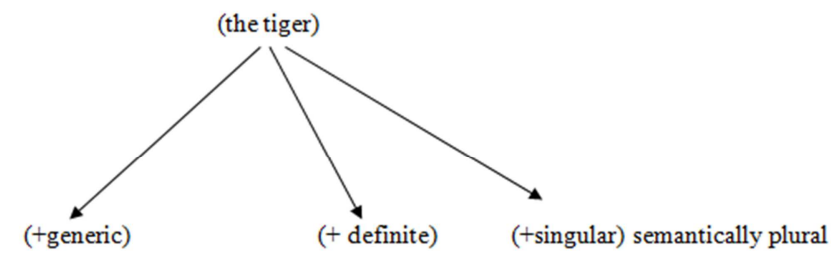

$([-\mathrm{SR},+\mathrm{HK}])$

The whole NP 'the tiger' and its usage in this context determine its grammatical and semantic identity; the Np 'the tiger' is functioning as a plural NP in this context. Hence, considering the NP barely based on Huebner's classification will result in a faulty identification of the NP as 'a tiger'.

\subsubsection{Ambiguity in the Use of Articles Due to the Manipulative Nature of English NPs to Serve Some Semantic Purposes}

The use of English articles in some English noun phrases sometimes differs to deliver different semantic purposes. For example, NPs including diseases nouns.

- If the speaker is generally speaking about a disease; then it is termed a non count noun and does not need either the definite or indefinite articles.

e.g flue is not dangerous if it is treated at early stages.

- If the speaker is referring to a specific event; then s/he uses the definite article 'the'.

e.g The flue I had last week was too tough.

- If the speaker is referring to the symptoms of a disease; then, s/he uses an indefinite article.

e.g I am suffering from nasal discharge. I am having a flue.

Thus, we could not totally depend on Huebner's Semantic Wheel in the classification of English noun phrases; neither to decide which English article to be used. English use of articles has many irregularities and exception which are inapplicable to such modeling.

Ambiguity in article use also occurs in some statements like 'A/ the woman cleaned a/ the room'. Both uses of articles are correct depending on the contexts they occurred in.

\subsection{Learners'Article System Backgrounds}

Huebner's Semantic model gives no consideration to the learners' article system backgrounds; especially in the cases that hold either-or. Thus, the application of Huebner's Semantic Model can lead to some doubtfulness in some cases. If we consider the English plural nouns 'women' and 
'men' as generic nouns ([-SR, +HK]), then $(\varnothing)$ or (the) are used to modify the nouns.

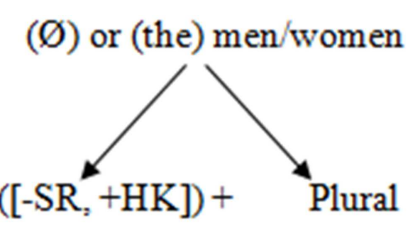

(Generic noun)

And if we consider the English plural nouns 'women' and 'men' as non-generic definite nouns, still we have to use the definite article (the) to modify the nouns.

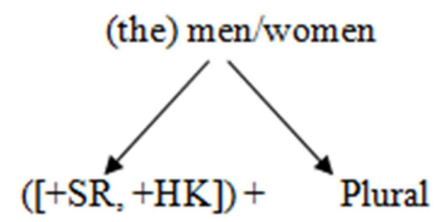

\section{(Non-generic noun)}

Accordingly, the noun phrases will have two possibilities 'The/Ø women live longer than the/ $\varnothing$ men' which is confusing to EFL learners. Those students of only definite articles backgrounds like Arabic English learners tend to overuse 'the' in such a context while native language speakers tend to consider them zero-articled Nps rather than articled in this context.

Geng (2010) found out that chinese learners' use of English articles is somehow affected by their mother tongue, chinese, article system. He claims that Chinese learners tend to associate the definite article with $[+\mathrm{HK}]$ contexts rather than $[+\mathrm{SR}]$ contexts, for the overuse of the definite article in $[+\mathrm{HK}]$ environments is significantly higher than that in [+SR] contexts.

Thomas (1989) pointed out Huebner (1983) and Master's (1987) claims that it needs further examination because of over-reliance on scarce [-SR, +HK] environments in the production of L2 learners. Parrish's (1987) experiment,on the other hand,claims that the is restricted to $[+\mathrm{SR}]$ as the is remarkably lacking in [-SR] contexts. Studies of Takahashi (1997) and Thomas (1989) claim that the is initially associated with $[+\mathrm{SR}]$ rather than $[+\mathrm{HK}]$ contexts.

The finding of Wing-man, C. (2005)t reveals referential definites $([+\mathrm{SR},+\mathrm{HK}])$ and generics $([-\mathrm{SR},+\mathrm{HK}])$ were relatively easy, whereas referential indefinites $([+\mathrm{SR},-\mathrm{HK}])$ was the most difficult. On the other hand, the results of the grammatical judgment test show generics and referential definites were the most problematic for the students, whereas referential indefinites ranked the second highest score. In addition, the findings reveal the was overgeneralized, particularly in the referential indefinite $([+\mathrm{SR},-\mathrm{HK}]) \mathrm{NP}$ environment. The results also show a hierarchy of difficulty among the various types of use of the, with cultural use and generic use being the most difficult followed in order by, structural use, situational use, and textual use.

\section{The Pedagogical Implications}

- Avoid teaching rules as irregularities and exceptions create some sort of confusions.

- Avoid referring to the similarities between L1 and FL because learners will develop negative learning strategies as a result.

- Teachers should give more attention to the semantic features of English articles in the different contexts.

- Articles should be taught as collocations in different contexts. This way, the learners will gradually reduce making overgeneralizations of the use of second language articles; or referring to their mother tongue article system to overcome the gap between the two systems.

- The four skills could be used integratedly to authenticate the use of articles in real life or life-like contexts, for example, in groups, writing a summary for short articles or filling the gaps of an interesting story...etc. Shalaby, A. I. (2014) claims that using articles properly needs a talent that can be enriched over time through keen attention to articles usages in listening, speaking, reading and writing contexts.

- Due to the complex nature of English article system, Articles can never be taught in a short period of time; instead, they need to be introduced gradually over a long period of time. Nevertheless, the articles can and should be taught (Master, 1997).

Students are the ones who, finally, deduce the rules.

\section{References}

[1] Geng, J. (2010). The Semantic Analysis of the Definite Article' Misuse by Chinese Learners of English. Asian Social Science, vol 6, pp180-184.

[2] Huebner, T. (1983). A longitudinal analysis of the acquisition of English. Ann Arbor, MI: Karoma Publishers, Inc.

[3] Master, P. (1987). A Cross-Linguistic Interlanguage Analysis of the Acquisition of the English Article System. Unpublished doctoral dissertation, UCLA

[4] Master, P. (1997). The English Article System: Acquisition, Function and Pedagogy. System, 25, 215-232.

[5] Parrish, B. (1987). A New Look at Methodologies in the Study of Article Acquisition for Learners of EFL. Language Learning, vol 37, pp361-383.

[6] Shalaby, A. I. (2014). English- and Arabic-Medium of Instruction and Second Language Acquisition of English Articles System by ESL Arab Sophomores in Sharjah, Master Thesis, The British University: Dubai, UAE.

[7] Ionin, T., Ko, H. and Wexler, K. (2004). Article semantics in L2-acquisition: the role of specificity. Language Acquisition, vol 12, pp3-69.

[8] Takahashi, T. (1997). Japanese Learners' Acquisition and Use of the English Article System. Edinburgh Working Papers in Applied Linguistics, vol 8, pp98-110. 
[9] Thomas, M. (1989). The Acquisition of English Articles by First and Second Language Learners. Applied Psycholinguistics, vol 10, pp 335-355.
[10] Wing-man, C. (2005). Acquisition of the English article system by Hong Kong students. Master Thesis, The Chinese University of Hong Kong: Hong Kong, China. 